\title{
A ESQUINA DO POVO DE ALT'LAM: APRIMORAMENTO RACIAL E MORAL NO MOVIMENTO ESPÍRITA NATALENSE
}

\author{
Antoinette Madureira ${ }^{1}$ \\ Luis Felipe Rios ${ }^{2}$
}

Resumo: A partir de um conjunto de dados obtidos em pesquisa, o texto deseja salientar uma face pouco examinada pelos estudiosos do espiritismo no Brasil: aquela dos grupos espíritas que cultuam extraterrestres. Examina a narrativa Rebeliāo de Lúcifer, escrita pelo médium potiguar Jan Val Ellam. Sustenta que esta atualiza noções importantes em relação a narrativas de salvação anteriores construídas pelo espiritismo. Destaca em especial o aprimoramento racial e moral através da reencarnação em distintos corpos humanos e em diferentes planetas. Examina-os a partir das noções de exílio planetário e de evolução racializada. Argumenta que Jan Val Ellam as atualiza através da categoria nativa Povo de Alt'Lam e através de bricolagem com outros campos semânticos, notadamente a ufologia e a ficção científica.

Palavras-chave: Espiritismo; Exílio Planetário; Evolução Racializada; Jan Val Ellam.

Abstract: It takes a set of data obtained while in research as a starting point, in order to point out a not so examined aspect of the spiritualism in Brazil by the scholars: the one about spiritualistic groups that worship extraterrestrial beings. It examines the Lucifer's Rebellion narrative, written by the potiguar medium Jan Val Ellam. It supports that this narrative updates important conceptions in comparison to previous salvation tales built by the spiritualism. It specially points out the racial and moral refinement theme through the reincarnation in distinct human bodies and in different planets. It examines these points based on planetary exile and racialized evolution ideias. It argues that Jan Val Ellam updates them

\footnotetext{
${ }^{1}$ Antoinette de Brito Madureira é doutora em antropologia e professora adjunta do Departamento de Serviço Social da Universidade Federal do Rio Grande do Norte - UFRN. E-mail: abmadureira@gmail.com

${ }^{2}$ Luís Felipe Rios é doutor em Saúde Coletiva e professor adjunto do Departamento de Psicologia, do Programa de Pós-Graduação em Psicologia e do Programa de Pós-Graduação em Antropologia da UFPE. E-mail: lfelipe.rios@gmail.com
} 
through his Alt'Lam People native category and through the blending with other semantic fields, notably the ufology and science fiction.

Keywords: Spiritualism; Planetary Exile; Racialized Evolution; Jan Val Ellam.

\section{INTRODUÇÃO}

Neste artigo, desejamos destacar a atualização de argumentações racialistas presentes na conformação do discurso de alguns grupos espíritas contemporâneos, particularmente através do culto a extraterrestres. Pretendendo oferecer uma discussão sobre aprimoramento racial e moral no espiritismo, o texto examina algumas das maneiras de como estas noçóes aparecem na literatura nativa espírita mais clássica e também nos escritos do médium Jan Val Ellam³ ${ }^{3}$ Esta é uma temática que entendemos ser importante, em particular, para a análise socioantropológica do movimento espírita brasileiro na atualidade e, de forma geral, para pensar as dinâmicas contemporâneas que envolvem expressões diversas de religiosidade no Brasil.

A questão racial não foi inicialmente pensada quando da construção do projeto que originou a Tese da qual este artigo é um desdobramento. Ela veio surgir a posteriori, na análise dos dados, quando por diversos caminhos a temática que conduzia a pesquisa, a saber, a construção das emoções entre espíritas adesos $^{4}$ e não adesos permitiu revelar que dadas emoções eram associadas a certos espíritos que apareciam racializados nos discursos nativos, como ciganas, índios, pretos velhos e entidades extraterrestres. Esta constatação fez

\footnotetext{
${ }^{3} \mathrm{O}$ presente artigo tem como ponto de partida a Tese de Madureira (2010). Jan Val Ellam é o pseudônimo do médium espírita, empresário, ufólogo e escritor potiguar, Rogério de Almeida Freitas, coordenador do Grupo Atlan, coletivo espírita natalense. Os escritos e palestras de Ellam e as reunióes do Grupo Atlan são examinados na Tese supracitada.

${ }^{4}$ Adeso: termo nativo espírita que significa "associado ao campo federativo espírita”, este último significando a FEB (Federação Espírita Brasileira) e as federações estaduais ligadas à FEB. Um centro espírita torna-se adeso quando se associa a uma dessas federações espíritas estaduais. $\mathrm{O}$ termo adesão também se refere à conversão. A esse respeito, ver Cavalcanti (1983).
} 
com que voltássemos a ler a literatura nativa que orientava as práticas espíritas, em busca das marcas raciais no pensamento espírita, objeto deste artigo.

A discussão sobre raça no espiritismo aparece desde autores como Bastide (1971), que, examinando o espiritismo de umbanda, identifica que nessa religião a luta racial, presente na dimensão social, passa a se expressar no campo do sagrado. A temática racial aparece também em Ortiz (1999), tratando do "embranquecimento" da umbanda, e em Cavalcanti (1983), que examina a presença das classes médias urbanas no espiritismo. Já a recente literatura antropológica, através de trabalhos como os de Sinuê Miguel (2009) e Lewgoy (2000), assinala a presença de militares e de certa classe média (funcionários públicos, médicos, professores) no movimento espírita brasileiro, o que pode sinalizar o espiritismo como uma religião de brancos em nosso país. A literatura também destaca, quando trata do mito fundador da umbanda, sobre a conhecida rejeição dos espíritas aos espíritos de cor, que são afastados de suas casas de culto para "descer" na umbanda (Giumbelli, 2002).

Buscamos aqui efetuar uma análise das condiçôes de produção do discurso espírita racializado em torno da temática dos extraterrestres em três tempos: inicialmente, focalizamos em escritos legitimados pela FERN 5 - mais especificamente $\operatorname{Kardec}^{6}$ e Chico Xavier ${ }^{7}$, em um segundo momento, em alguns escritos cuja leitura não é incentivada pela FERN, mas que no entanto é lida pelos espíritas - Edgard Armond ${ }^{8}$ e Hercílio Maes ${ }^{9}$ e, em um terceiro momento, nos escritos de Jan Val Ellam. Assinalamos a importância de olhar os escritos deste último médium como possibilidade de iluminar questôes que passam desapercebidas, quando focamos apenas nos textos aceitos pela federação, e sinalizamos que não incluir o universo dos não adesos seria uma mutilação, mais do que um recorte metodológico,

\footnotetext{
${ }^{5}$ FERN: Federação Espírita do Rio Grande do Norte. Fundada a 29 de abril de 1926; adesa à Federação Espírita Brasileira (FEB).

${ }^{6}$ Allan Kardec (1804-1869). Pedagogo francês, criador da doutrina espírita.

${ }^{7}$ Francisco Cândido Xavier (1910-2002), médium espírita mineiro. Para a sua carreira, Lewgoy (2000) e Stoll (1999 e 2003).

${ }^{8}$ Edgard Armond (1894/1982), militante espírita paulista.

${ }^{9}$ Hercílio Maes (1913-1993), médium espírita paranaense.
} 
já que estes últimos são falados todo o tempo no movimento espírita, seja enquanto modelos alternativos - e negativos - de comportamento para os espíritas tradicionais seja enquanto lugares de "fuga", onde se buscam recursos - simbólicos, terapêuticos - para lidar com aquilo que a ortodoxia espírita não consegue dar conta.

De início, apresentamos o lugar do médium Jan Val Ellam e de seu grupo ante o movimento espírita natalense; em seguida, tratamos de como na tradição espírita ${ }^{10} \mathrm{o}$ aprimoramento moral e racial é situado, especialmente em Kardec e Xavier. Logo após, trazemos os escritos de Armond e Maes que tratam do mesmo tema, para então situarmos a narrativa de Ellam acerca de aprimoramento moral/racial. Em seguida, salientamos a noção de "esquina do povo de Alt'Lam", para examinar a conclusão da narrativa de Ellam e, por fim, examinamos as diferenças e semelhanças entre adesos e não adesos em relação à evolução racializada, sempre em torno do tema dos extraterrestres.

\section{"PREPARADOS PARA A ATERRISSAGEM": O GRUPO ATLAN E A VOLTA DE JESUS NO DISCO VOADOR}

Era o início do ano de 2007 e a segunda vez que participávamos da reunião do grupo Atlan, e eis que, nesse dia, Graça, uma das médiuns do grupo, trouxe um livro para nos emprestar; disse-nos que deveríamos lê-lo, para "entender sobre os nossos mentores e a nossa tarefa". Era um livro psicografado por certo Herbert Speer e intitula-se A Grande Mensagem Celeste de Ashtar Sheran à Humanidade da Terra. Por esta mesma época, Luiz, outro médium, ofereceu-nos mais um livro, intitulado $A$ Sétima Trombeta do Apocalipse: a volta de Jesus, da autoria de Jan Val Ellam, o coordenador do grupo. Também orientou-nos a que nos registrássemos em uma comunidade virtual na internet, chamada de Fórum Comunidade Família Ascensão ${ }^{11}$. Disse que a leitura e a participação nessa comunidade virtual iriam nos "ajudar"

${ }^{10}$ Para “tradição espírita”, Stoll (2002).

${ }^{11}$ Site Fórum Comunidade Família Ascensão. Disponível em http://nominato.asiafreeforum.com/f1-comunidade-familia-ascensao-http-nominatocombr-forum-index. Acesso em 05 out 2009. 
a estar "prontos, antes da aterrissagem". Ora, a aterrissagem era a volta de Jesus Cristo à Terra em um disco voador, como "já deveríamos saber”.

De fato, já conhecíamos há algum tempo esta profecia, por causa de nossa circulação entre o movimento espírita natalense: estava previsto que Jesus voltaria à Terra naquele mesmo ano, até o final do mês de novembro. $\mathrm{O}$ autor da profecia, Jan Val Ellam, o coordenador do Atlan, era um médium que se comunicava com Lúcifer - também chamado de Yel Luzbel ${ }^{12}$, e com numerosos extraterrestres, os mesmos que estavam a preparar a chegada triunfal de Jesus, que voltaria à Terra junto com outros personagens mencionados na Bíblia, não apenas em um, mas em centenas de discos voadores que seriam, então, vistos nos céus de todo o nosso planeta. A chegada do Cristo, segundo conta Ellam, caracterizava-se como uma "ajuda direta" ${ }^{13}$ : Jesus chegaria em breve para anunciar a expulsão dos inadequados, encerrando também uma guerra milenar, a Rebelião de Lúcifer. Jesus trazia a tarefa de concluir o conflito, intervindo de forma definitiva em nosso planeta, no sentido de retirar dele todos os indivíduos ainda vinculados às forças do Mal, num processo chamado de Transição Planetária.

Fundado no final dos anos oitenta ${ }^{14}$, e registrado como Sociedade Civil Sem Fins Lucrativos, em dezembro de 1996, o Grupo Atlan de Natal, ou simplesmente "o Atlan", reúne-se mensalmente no auditório de uma escola de ensino fundamental de Natal. Nas reunióes, há a presença assídua de aproximadamente sessenta membros, mas se contarmos também com os participantes eventuais o grupo detém por volta de duzentos componentes

\footnotetext{
12 Yel Luzbel é um personagem resgatado dos mitos judaico-cristãos para a cena espírita, tomando lugar na narrativa contada por Jan Val Ellam, como descreveremos mais à frente neste artigo.

${ }^{13}$ A categoria nativa "ajuda direta" designa a chegada de seres evoluídos em naves espaciais, para auxiliar as humanidades dos vários mundos retardados evolutivamente. Jan Val Ellam diferencia ajuda direta (chegada nas naves) e indireta, através da reencarnação. (Ellam, 1996, p. 57).

${ }^{14}$ Os adeptos contam que as primeiras reuniōes do Grupo Atlan, quando ainda não detinha esse nome, davam-se na residência de um dos participantes, e que, após alguns anos o grupo sentiu a necessidade de se registrar como Sociedade Civil Sem Fins Lucrativos.
} 
em sua totalidade. A única atividade desenvolvida pelo Atlan é a palestra com Jan Val Ellam.

Chamados carinhosamente por Jan Val Ellam de "Povo de Alt'Lam", o Atlan - junto a outros grupos que seguem Ellam - carrega a tarefa de avisar à humanidade sobre a transição planetária. Compreendendo que a guerra entre Jesus e os exércitos do Mal permanece em nossos dias e se expressa em todos os conflitos humanos, recebem relevo em suas reunióes o tema da guerra, especialmente a segunda guerra mundial e os conflitos bélicos do oriente médio. Também há certo interesse nos universos da astronomia ${ }^{15} \mathrm{e}$ da ufologia, principalmente em torno da procura de vida em outros planetas e sobre OVNIs.

É importante apresentar rapidamente o médium coordenador do grupo. Graduado em administração de empresas, Ellam trabalhou quinze anos na Caixa Econômica Federal, onde ocupou funçōes gerenciais. É hoje diretor executivo da Federação do Comércio de Bens, Serviços e Turismo do Rio Grande do Norte e também diretor de um grupo português que detém empreendimentos turísticos no litoral do Rio Grande do Norte. Interessado por ufologia e muito conhecido pela comunidade ufológica brasileira, tendo, segundo conta, investigado casos de ataques de ETs a humanos no sertão nordestino, ele é criador do Projeto Orbum, que tem como objetivo "[...] articular ufologia e espiritualidade [...]" e que traz como escrito básico a "declaração dos princípios da cidadania planetária", em que se encontra a intenção de se construir na Terra "um comportamento fraterno, para além das fronteiras geopolíticas, religiosas e étnicas" ${ }^{\text {" }}$.

É também colaborador das revistas brasileiras Comciência, UFO, O quê? e da portuguesa Clássicos e Modernos. Tem participação em dois programas de rádio veiculados semanalmente, aos domingos à noite: o Projeto Orbum, da Rádio Boa Nova, de São Paulo (SP), acessado através do link www.radioboanova.com.br, e o Conversas sobre a Espiritualidade, da Rádio

\footnotetext{
${ }^{15}$ Há, inclusive, um astrônomo, professor universitário, entre os membros deste grupo.

${ }^{16}$ Para o manifesto completo, ver http://www.orbum.org/manifesto/. Acesso em 21 jul 2011.
} 
Poty, de Natal (RN). Tem quinze títulos publicados ${ }^{17}$ e faz regularmente conferências internacionais, abordando a já mencionada transição planetária.

Articulando ao seu modo noções encontradas em Kardec e Chico Xavier, com fragmentos pinçados de outros campos semânticos, os livros de Ellam o fazem conhecido junto a certa vertente do movimento espírita, notadamente admiradores das UFO Religions ${ }^{18}$ e de certa literatura sobre conflitos bélicos.

Ora, na época da pesquisa, intrigava-nos a influência de Ellam no movimento espírita natalense, já que as reuniōes do Atlan em Natal são frequentadas por dirigentes de diferentes casas espíritas. Lembramos ao leitor que tomamos conhecimento das ideias de Ellam "pelos corredores" de centros adesos à FERN; assinalamos que em nenhum destes o nome de

${ }_{17}$ Os assinados sob o pseudônimo Jan Val Ellam são a trilogia Reintegração Cósmica (1996), Caminhos Espirituais (1997) e Carma e Compromisso (1998), além de O Sorriso do Mestre (1998), Nos Céus da Grécia (1998), Recado Cósmico (1999), Nos Bastidores da Luz (2000), Muito Além do Horizonte (2001), Jesus e o Enigma da Transfiguração (2002), Fator Extraterrestre (2004), A Sétima Trombeta do Apocalipse: a volta de Jesus (2005), O Testamento de Jesus (2006) e Nos Bastidores da Luz II (2006). Publicou ainda, em 2005, utilizando o nome Rogério de Almeida Freitas, Inquirição Poética e Teia do Tempo, este último em coautoria com o astrônomo José Renan de Medeiros, da Universidade Federal do Rio Grande do Norte. Conta, segundo nos disse, com um grande volume de obras em andamento e algumas prontas, apenas aguardando "autorização dos mentores" para serem publicadas. Além do Brasil, algumas de suas obras foram publicadas em Portugal, África do Sul, Austrália, Angola, Moçambique, Inglaterra e Rússia. Ele também é fundador da Editora Zian, que publica parte de seus livros.

${ }^{18}$ Partridge (2003) chama de UFO Religions grupos espiritualistas como a Raelian Church (no Brasil chamada de Movimento Raeliano), a Unarius Academy of Science, a Aetherius Society e a Heaven's Gate, que defendem, de uma maneira geral, a existência de seres extraterrestres na direção da história da humanidade, além de sustentar que o planeta Terra faria parte de certa "comunidade galáctica" e que um futuro de paz e harmonia em nosso planeta está ancorado na ajuda de ETs, mais precisamente em suas supostas capacidades tecnológicas e espirituais. Também defendem a existência de certa conspiração entre os governos da Terra para ocultar a presença dos ETs entre nós. Sobre as UFO Religions, além de Partridge (2003), ver Grunschloß (2002), Lewis (1995) e Vallee (1979), dentre outros. 
Jan Val Ellam era desconhecido nem tampouco tratado com indiferença, ainda que ele seja desvinculado de casas tradicionais.

Porém, algum tempo de inserção neste campo já é suficiente para entender que sua presença é pouco tolerada pela federação; esta recrimina publicamente algumas práticas de seu grupo, como a convivência mediúnica com o espírito de Lúcifer, a crença na volta de Jesus no disco voador, o uso do nome da doutrina espírita como referência e o fato de que Ellam é tido pelos seus seguidores como a reencarnação de Allan Kardec.

$\mathrm{Na}$ verdade, um mapeamento ainda que superficial da influência de Ellam deve ir além da cidade de Natal, pois o grupo Atlan está criando filiais: há poucos anos surgiram o Grupo Atlan de Campo Grande (MS) e o de Vitória da Conquista (BA), grupos que tiveram a presença de Ellam em seu processo de fundação. Há também grupos que o seguem em São Paulo e Rio de Janeiro e fora do Brasil, como em Portugal, na Itália ${ }^{19}$ e em Angola ${ }^{20}$, para onde o médium frequentemente viaja, a fim de ministrar conferências. Na repercussão de suas ideias, deve também ser analisado o volume de vendas de seus livros, disponíveis para comercialização on-line ${ }^{21}$ e a veiculação de suas palestras através do site Orbum $^{22}$.

Este é um campo que não tem sido estudado frequentemente pela ciência. Lembramos, contudo, que o culto de extraterrestres no espiritismo já foi salientado por Inácio da Cruz (2007), que examinou a carreira do médium Chico Monteiro, um "mix de terapeuta holista, escritor, músico, inventor, catalisador de seres angelicais, comunicador, benzedor" (Cruz, 2007). Monteiro afirma incorporar o espírito do médico alemão Dr. Fritz, assim como andar de disco voador, tendo sido, segundo conta, abduzido em uma nave espacial. Também relata receber dos comandantes Ashtar e

${ }^{19}$ O "Gruppo Atlan Italia", com sede em Milão, foi fundado no mês de junho de 2011, em cerimônia em que Jan Val Ellam, presidente honorário, fez-se presente. O grupo tem como coordenador um italiano que morou alguns anos em Natal.

${ }^{20} \mathrm{O}$ grupo de Luanda tem como figura mais conhecida uma médium de pseudônimo Val Eom, que publicou um livro tratando do que diz ser o significado da "reintegração cósmica da Terra" e da "volta de Jesus" para o continente africano. (Val Eom, 2005).

${ }^{21}$ Alguns livros de Ellam também estão disponíveis para cópia gratuita pela internet.

${ }^{22} \mathrm{O}$ link do site Orbum é http://www.orbum.org/. Acesso em 21 jul 2011. 
Rajneve - extraterrestres - "ensinamentos variados". Monteiro narra o episódio de sua abdução em livro (Monteiro, 1995). Para a carreira de Chico Monteiro, ver Cruz (2007).

Há ainda o trabalho de Veronese (2006) sobre o culto religioso a ETs no Brasil. Esta pesquisadora efetuou, pioneiramente, pesquisa junto a Jan Val Ellam, em um grupo que o segue em São Paulo. A pesquisa de Carly Machado (2006) sobre o movimento raeliano é também emblemática, pois esse grupo, além de cultuar extraterrestres, traz como uma de suas marcas etnográficas o acionamento de noções do âmbito da ciência e da ficção científica, incorporando-os ao seu sistema de crenças.

Configurando-se como as bases sob as quais Ellam escreve, no próximo ponto deteremos-nos nas maneiras como $\mathrm{Kardec}^{23}$, e posteriormente Chico Xavier, Edgard Armond e Hercílio Maes, abordam o aprimoramento universal de planetas e seres humanos, estes últimos dispostos em raças.

\section{APRIMORAR-SE RACIALMENTE OU SER ELIMINADO: DO "EXÍLIO CÓSMICO"}

Para Kardec (1997), todos os orbes ${ }^{24}$ do universo são dispostos em categorias evolutivas e habitados por humanos dispostos em raças também distintas em padrões evolutivos. No extremo inferior, encontram-se os orbes primitivos, sucedidos pelos de expiaçôes e de provas (a Terra é um destes), mais adiante os de regeneração e enfim os superiores, em que só existe o Bem. A "sucessão e o aperfeiçoamento das raças" ocorre em todo o universo

\footnotetext{
${ }^{23}$ Estes elementos constam em O Livro dos Espiritos, no Evangelho Segundo o Espiritismo e em $A$ Gênese. Vale aqui assinalar, junto com Stoll, que "a participação de Kardec na constituição da doutrina é muito mais extensa do que ele próprio sugere" (Stoll, 2003 p. 48); nesse sentido, pode-se dizer que ele não apenas organiza as mensagens dos espíritos, como é dito pelos adeptos da doutrina, mas também imprime sua marca pessoal nas interpretações que faz sobre um conjunto de temas de ordem religiosa, buscando harmonizá-los com as descobertas científicas de sua época, sendo, assim, mais que apenas um codificador. (Stoll, 2003, p. 48).

${ }^{24}$ Orbe: categoria nativa espírita, significando os planetas com sua população de espíritos encarnados e desencarnados (vivos e mortos).
} 
(Kardec, 1997, p. 127), principalmente através da reforma intima ${ }^{25}$. Porém, diz Kardec, que, frequentemente, um planeta progride muito e os indivíduos atrasados podem dele ser retirados e enviados a outro, menos evoluído: é o degredo planetário de indivíduos inadequados (Kardec, 1997, p. 123, p. 125). Devemos lembrar que nos escritos de Allan Kardec não há o delineamento de um mito de origem, assim como não há o relato de uma revelação divina a algum messias ou profeta (Stoll, 2003, p. 40). A cosmogonia é formulada por Chico Xavier, a partir dos anos 1930, no Brasil.

A articulação da educação emocional a uma limpeza planetária, tratada por Kardec, reaparece no espiritismo brasileiro no ano de 1939, quando da publicação de $A$ Caminho da Luz, de Chico Xavier, autoria espiritual de Emmanuel. Atente-se que mesmo antes de Xavier, os romances espíritas já traziam uma reapropriação mítica da história (Aubrée, 1994; Lewgoy, 2000); destacando períodos como o antigo Egito e a revolução francesa, diferentes conjunturas são lidas à luz da doutrina espírita. Xavier é, porém, um divisor de águas, pois ele vai além, apresentando aos espíritas um mito de origem, que até então sua religião não detinha. A partir de $A$ Caminho da Luz, os espíritas vão passar a citar "Capela” como o "paraíso perdido".

Neste livro, lemos que Jesus é o responsável pela criação de nosso planeta e por semear aqui todas as formas de vida, em especial as "raças" dos primeiros "humanoides" (Xavier, 1999, p. 18). É então apresentado o sistema estelar de Capela, que havia chegado a grande desenvolvimento, trazendo, porém, como obstáculo, a presença de "alguns milhōes de espíritos rebeldes". Sendo necessário o saneamento do planeta, estes seres são encaminhados à Terra, não sem antes se reunirem com Jesus Cristo (Xavier, 1999, p. 35), que lhes explica o seu destino: por causa de seu crime do orgulho, serão exilados, sem data de retorno, na Terra, mundo primitivo, junto a raças ignorantes e atrasadas (os "primeiros humanoides" criados por Jesus). Seriam os mais evoluídos deste planeta, e trabalhariam em seu adiantamento. Que jamais esqueceriam o "paraíso perdido" nos firmamentos distantes; porém,

\footnotetext{
${ }^{25}$ Para a análise da reforma íntima espírita, culto interno que objetiva a transformação da pessoa moral, Cavalcanti, 1983, p. 50-51.
} 
diz Jesus, sentiriam a sua presença e o seu apoio cotidianos, e, além disso, promete-lhes, teriam a sua vinda, no porvir.

Xavier diz que os capelinos fundam as raças adâmicas (concernentes à história de Adão e Eva), sendo a raça ariana uma das mais fundamentais, pois teria lançado "os marcos da civilização europeia" (Xavier, 1999, p. 26, 35-36). Os capelinos vão impulsionar o surgimento de todas as grandes civilizações antigas; alguns deles, após milênios, retornam a Capela; outros ainda vivem na Terra, e presenciarão o momento de transição deste planeta, no "crepúsculo de civilização", que Xavier situa no século XX (Xavier, 1999).

Em 1949, Edgard Armond escreve Exilados de Capela, em que conta mais detalhadamente a "saga dos capelinos", de Xavier: ele recupera da angiologia cristã a figura de Lúcifer, que é levado "pelo orgulho" a cair na Terra (Armond, 1995). Também prevê que, "em breve", aproximar-se-á da Terra um planeta de aura etéreo-astral três mil e duzentas vezes maior que ela, causando a verticalização do seu eixo e "sugando" daqui os indivíduos inadequados para o "bojo incomensurável do passageiro descomunal”; só um quarto dos habitantes da Terra - os brandos e pacíficos, nela permanecerão e serão os responsáveis por construir uma nova civilização (Armond, 1995, p. 55-56).

Poucos anos depois da publicação desse livro de Armond, são publicados os primeiros livros de Hercílio Maes, autoria espiritual de Ramatís ${ }^{26}$. Maes

\footnotetext{
${ }^{26}$ Ramatis, Ramatís, Rama-tys ou Swami Sri Rama-tys é o nome atribuído pelos espíritas a certo mestre espiritual hindu. Os médiuns Hercílio Maes, América Paoliello Marques, Maria Margarida Liguori, Wagner Borges, Jan Val Ellam, Norberto Peixoto, Dalton Roque e Hur-Than de Shidha são alguns dos que afirmam terem se comunicado com Ramatís. A rejeição de parcela do movimento espírita brasileiro ao nome de Ramatís, particularmente por parte da FEB, é clara, sendo emblemáticos, por exemplo, os escritos de J. Herculano Pires (1914-1979, escritor espírita paulista), que, publicando no extinto jornal Diário de São Paulo, entre os anos de 1969 e 1970, uma coluna sob o pseudônimo de Irmão Saulo, classificava Ramatís como espirito mistificador, um dos "falsos profetas da erraticidade". A rejeição a Ramatís mantém-se na atualidade, no meio espírita mais ligado à $\mathrm{FEB}$ e às federações espíritas estaduais. Uma expressão desta é a produção de Artur Ferreira (1997 e 2012), em que crítica a Ramatís se dá em nome de certo "movimento pela pureza doutrinária”.
} 
retoma e desenvolve a profecia sobre o "planeta higienizador": este levará consigo dois terços da humanidade, que emigrará por padröes, indo constituir raças particulares no planeta intruso: as raças de "fanáticos, intransigentes, mercantilistas e orgulhosos", das "doutrinas religiosas", serão reunidos em um grupo distinto. Já as raças de "avaros, desonestos, capciosos e astuciosos" formarão outro grupo; da mesma forma, as raças de "cruéis, impassíveis, malfeitores e semeadores de sofrimento"; e também os "luxuriosos, pervertidos, desvirtuadores da moral costumeira" e, finalmente, as raças de "zombeteiros, mistificadores, malbaratadores de bens alheios". (Maes, 1996, p. 285-286). Maes assinala a importância desta limpeza para que logre sucesso a "segunda vinda" do Cristo, o Arcanjo Planetário da Terra, no terceiro milênio (Maes, 1996, p. 291), e enfatiza a centralidade da Grande Fraternidade Branca e seus mestres, como Saint-Germain ${ }^{27}$, a impulsionarem a ascensão de nosso planeta (Maes, 1996, p. 363).

\section{JAN VAL ELLAM E A REBELIÃO DE LÚCIFER}

Diferentes elementos presentes em Kardec, Xavier, Armond e Maes dão fundamento à narrativa de Ellam. Em sua "trilogia"28, ele retoma a construção kardequiana de que, para nosso planeta evoluir, alguns devem ser expulsos. Recupera também a ideia de Xavier de que isso já ocorreu há milhares de anos, em Capela, e reinstitui a figura de Lúcifer, mencionada por Armond, para expor a sua versão da história.

\footnotetext{
${ }^{27}$ Saint-Germain é uma entidade cultuada no Grupo Atlan, fazendo parte do que os adeptos chamam de "Panteão de mestres ascensos", do qual também faz parte Ramatís, Jesus Cristo e o extraterrestre Ashtar Sheran. No Brasil, sua figura é cultuada por alguns grupos componentes do movimento da nova era, como a Fraternidade dos Guardiães da Chama (Summit Lighthouse do Brasil), o Movimento Eu Sou (I AM Activity), a Ordem Rosacruz e o Movimento da Consciência Suprema Una, dentre outros.

${ }^{28}$ A história da Rebeliāo de Lúcifer consta nos três primeiros livros de Ellam, que intitulam-se: Reintegração cósmica - os anjos decaídos, Caminhos Espirituais - Livre Arbitrio e Carma e Compromisso - Filhos das Estrelas. Eles compõem uma série, intitulada Queda e Ascensão Espiritual, também chamada de trilogia de Ellam pelos nativos.
} 
Conta então que, há três milhões de anos, a Terra era um planeta primitivo, mas prestes a deixar de sê-lo, pois nela seria construída uma "base", um portal de saída rumo ao espaço exterior, o que transformaria o nosso planeta em "lugar de confraternização de várias raças planetárias evoluídas" (Ellam, 1996, p. 19). A razão dessa construção era a posição estratégica da Terra, na "esquina da galáxia". Era este o Projeto Planeta Azul, que, infelizmente, não se realiza em virtude da irrupção de uma guerra galáctica, a rebelião de Lúcifer, que põe o projeto de construção da mencionada "base" a perder (Ellam, 1996, p. 26; Ellam, 1998, p. 17-32).

$\mathrm{Na}$ história dessa guerra, um dos personagens centrais é o próprio médium, que na época se chamava Val Ellam, morava no planeta Zian, em Capela, e convivia diretamente com Jesus (Ellam, 1996, p. 36). Junto com outros setecentos e trinta e seis indivíduos, chamados de família Val, Ellam efetuava um trabalho de "codificação". Para tal, pilotava uma nave espacial, e quando ia visitar Jesus em Orbum, o planeta onde este morava, levava consigo o "seu velho mestre codificador"29 (Ellam, 1998, p. 37-38).

É quando uma doença acomete centenas de indivíduos deste sistema, fazendo-os duvidar da existência de Deus. Liderados por Yel Luzbel, Lúcifer, do planeta Alt'Lam, os infectados empreendem uma revolta armada contra Javé, espírito criador de nosso universo. Ocorre então a guerra já mencionada, que dura milênios e envolve dois exércitos: os de Javé e os de Lúcifer; este último é derrotado e como castigo, seus membros são expulsos de Capela e exilados no planeta Terra, onde aportam a bordo de discos voadores. Assinalamos o peculiar lugar onde aterrissam as "hostes luciferinas": as naves trazendo o exército derrotado ancoram em uma base que leva o nome de Alt'Lam, situada em Atlântida, na esquina do oceano atlântico (Ellam, 1998, p. 165). Neste ponto do relato, a história repete-se: recordando o destino de glórias guardado para o "planeta azul" e há milênios desperdiçado, cabe dessa vez aos extraterrestres aprisionados na Terra, ainda que contaminados pela doença do orgulho, aproveitarem a base atlante para levar o nosso planeta à ascensão na hierarquia dos mundos. Porém, com a

${ }^{29}$ Atente-se que codificador é um termo caro aos espíritas, já que designa precisamente a figura de Allan Kardec. 
derrocada do império atlante, o plano da ascensão mais uma vez fracassa, e esta base desaparece.

Mas a narrativa de Ellam continua, até os nossos dias, e então percebemos que algo da sina dourada anunciada para o "planeta azul" e depois para a base atlante permaneceu, enraizando-se em nova esquina e em mais uma promessa de felicidades no infindável plano da ascensão. Na verdade, é a mesma Alt'Lam, renomeada, que ressurge, pois Ellam nos diz que "muitos milênios depois", já em nossos dias, aparece, também na esquina do Atlântico, a cidade de Natal, que traz as mesmas letras de Alt'Lam, "[...] num anagrama que esconde bem mais do que aparentes casualidades" (Ellam, 1998, p. 169-170).

Ellam então conclui sua narrativa no aguardado retorno de Jesus Cristo ao planeta Terra, a bordo de um disco voador, em uma ajuda direta. A nave de Jesus aportará na cidade de Natal: este evento encerrará a Rebelião de Lúcifer e deve assinalar a inauguração da Terra enquanto "mundo de regeneração".

\section{A ESQUINA DO POVO DE ALT'LAM}

Devemos atentar para o leitor que o imaginário natalense é permeado pela ideia de "esquina do atlântico", que traz uma das faces importantes de Natal, cidade cravada em lugar reconhecido como geograficamente especial pelos colonizadores portugueses, depois pelos holandeses e, finalmente, pelos militares brasileiros e norte-americanos que, em 1943, instalaram nela a Parnamirim Field, uma das grandes bases militares norte-americanas construídas fora dos Estados Unidos na época da segunda guerra mundial, ou simplesmente "a Base", como a chamaram os natalenses da época.

A chegada em Natal das tropas vindas dos EUA trouxe uma profunda transformação espacial para uma cidade, que só se comunicava com o resto do mundo pelo mar ou pela via férrea: foram os militares norte-americanos que, em seis meses, construíram a primeira via expressa da cidade, a Parnamirim Road, apelidada pelos natalenses de "a pista". Ela tinha seu início na Base de Parnamirim Field e seguia por vinte quilômetros até o porto, atravessando, comunicando e por fim redesenhando toda a cidade. $\mathrm{Na}$ 
manutenção da "base", entrou mão de obra local: por 15 centavos de dólar ao dia, "todo mundo" queria "trabalhar para os americanos", em serviços de limpeza e de construção civil. (Lopes, 1997, p. 38-39). Também alguns dos produtos de primeira necessidade passaram a ser adquiridos localmente, movimentando - e inflacionando - o comércio. Bailes foram organizados nos poucos clubes da cidade, surgiram cursos de inglês e, com a construção da Parnamirim Road, a classe média animara-se a comprar jeeps e caminhōes, e com eles passeava pela "pista". Para uma cidade que até então detinha poucas ruas calçadas, este era um desfile inédito (Lopes, 1997).

Ao lado da euforia pelo dólar que circulava rapidamente pelo comércio local e pelas boates recentemente abertas para atender ao fluxo dos gringos, havia também o clima de guerra a assombrar a cidade que dez anos antes era uma província de apenas três bairros (Cascudo, 1999; Onofre Jr., 2002). Os mais velhos falam em toque de recolher e blecautes, pois a "base dos americanos" era "[...] lugar visado pelos nazistas".

O término da guerra não ocasionou uma desocupação imediata da cidade pelos americanos, e a base de Parnamirim só foi entregue, definitivamente, ao Brasil, em outubro de 1946, mais de um ano após o fim do conflito, mas então algo havia mudado. Como no conto sobre o afogado mais bonito do mundo - o gringo morto jogado em uma praia miserável de uma aldeia miserável, que contrariando todas as expectativas é acolhido pelas crianças, admirado pelas mulheres e então velado e pranteado por todos, recebendo os funerais mais bonitos, de tal sorte que após o cortejo final onde seu corpo é atirado às escarpas, a própria cidade é rebatizada em sua homenagem (García Márquez, 1998), também a cidade de Natal, submersa durante três formidáveis anos na multidão de gringos fardados não seria mais a mesma sem eles.

No mito galáctico que tentamos narrar, Ellam recupera dois elementos que remetem ao período da segunda guerra em Natal: a base militar e a relação com os estrangeiros. Desta maneira, ao tratar de Atlan, a base construída em uma esquina para abrigar forasteiros envolvidos em uma guerra, Ellam toca nas peculiares lembranças dos natalenses sobre a sua própria base, elemento central para a constituição da identidade potiguar, fazendo 
Natal comparecer como mais um desdobramento do lugar de origem, a terra da promissão: a partir dela é recontada a história do minúsculo e isolado planeta azul, na esquina da galáxia, invadido por seres de outros mundos, que trouxeram progresso material e desenvolvimento tecnológico, e também conflito e desagregação.

Neste sentido, o personagem que escolheu - o ET - é perfeito, já que ele se situa em certa zona ambígua: por um lado, o extraterrestre é a própria alteridade, o estrangeiro por excelência, o outro absoluto, pois ele não apenas traz uma cultura diferente, mas vem de outro planeta, veste outro corpo (Renard, 1984; 1987), e por outro lado - na medida em que supomos que poderemos nos comunicar com ele, por entendermos que ele possivelmente teria racionalidade - o ET também está no limite entre alteridade e identidade (Aranha Filho, 1990).

É a partir da "ajuda direta" destes estrangeiros que Ellam oferece sua ideia de expurgo planetário: ele nos diz que a doença do orgulho trazida pelo exercito de Lúcifer se transformou em endêmica na Terra, não podendo mais ser curada, a não ser com a expulsão dos doentes, processo que já se encontra em fase de conclusão e levará dois terços de nossa população para planetas “inferiores" (Ellam, 2000). Já curados, porém, os setecentos e trinta e seis indivíduos que faziam parte da família Val, e que são atualmente os seguidores de Ellam, irão ajudar neste expurgo.

Assim, ao final, a narrativa, que nos apresenta diferentes "esquinas", conclui-se com o elogio de um povo, que traz em seus ombros a tarefa de conduzir a limpeza e a ascensão de um planeta a um destino triunfante. Nesta narrativa, carregada de elementos morais, a história do exílio planetário que se inicia com Kardec é atualizada por Ellam a partir do povo de Alt'Lam.

\section{EVOLUÇÃO PLANETÁRIA E APRIMORAMENTO RACIAL NO ESPIRITISMO}

Há certas marcas ideológicas que possibilitam os enunciados se articularem da maneira como os vimos em Kardec, Xavier e Ellam (Pêcheux, 1990; 
Bakhtin, 1997). As ideias de evolução e de aprimoramento racial e moral do espiritismo, à época de Kardec, ancoram-se em certo contexto social e ideológico, o do surgimento da noção de raça em suas capacidades físicas e morais no âmbito da ciência (Schwarcz, 2001). Kardec incorpora em seus escritos, que queriam se dizer científicos, essa ideia: ampliando a noção de evolução para todo o universo, tematiza o caminhar dos entes, vida após vida, no processo de humanização, e nos fala de um aperfeiçoamento moral condicionado pelas raças, das mais simples às mais superiores.

Há aqui também a categoria nativa reencarnação, que traz um segundo determinismo: o indivíduo, além de encarnar em corpos racializados, ainda traz um karma, adquirido em outras vidas, a lhe constranger as açôes, o que faz com que a atualidade seja uma "resultante diacrônica de uma sequência narrativa de pagamentos de dívidas e provaçôes escolhidas" (Lewgoy, 2000), aquilo que Lewgoy (2000) denomina de "sistema da dívida". Porém, a noção espírita de livre-arbítrio parece, a uma primeira vista, relativizar a rigidez das "leis evolutivas" raciais e do karma, a partir da categoria nativa reforma intima. Pode-se dizer que há, pois, no espiritismo, desde Kardec, esta convivência contraditória entre determinismo e livre-arbítrio (Cavalcanti, 1983).

No espiritismo brasileiro, a contradição mantém-se, e a discussão sobre raças também, mas se o ideário científico que dá fundamento ao espiritismo francês é o da eugenia, ao chegar ao Brasil, estas ideias parecem se confrontar com o problema nacional do "país de mestiços". Assim, na época em que surge o livro $A$ Caminho da Luz, de Chico Xavier, a questão é como sustentar uma evolução espiritual, em que a melhoria das raças é uma das condições, num país tido como degenerado racialmente, como o Brasil, pois as marcas da mistura racial e das epidemias que grassavam aqui se remetiam reciprocamente na mentalidade europeia - afinal, doença e raça estavam apreendidas a partir de uma mesma matriz (Costa, 1999). 
A saída do espiritismo, mais uma vez às voltas com o determinismo racial, que, se aceito in totum impossibilitaria a evolução no Brasil ${ }^{30}$, foi focar no melhoramento do indivíduo, como uma espécie de técnica de si (Foucault, 1994), uma disciplina que, se bem internalizada, poderia subjugar a força da carne. Dentre as várias possibilidades teórico/práticas que já estavam em andamento no país, no meio científico da época, os espíritas, assim, afinam-se mais facilmente ao eugenismo neolamarckista ${ }^{31}$, que fundava no meio os caracteres adquiridos e passados de geração a geração, enfatizando intervenções externas e "pouco genéticas" no processo de evoluir, a partir da ideia de reforma intima.

Já presente em Kardec, no modelo de Chico Xavier, a reforma íntima mantém-se, aprimorado pelo "circuito de intercessão e graça" (Lewgoy, 2000), absorvido do catolicismo popular por Xavier, e fazendo com que a reforma íntima neste último se diferencie da de Kardec (Lewgoy, 2000). Ora, em Kardec, opera o sistema da divida: a reforma íntima é efetuada através de sacrifícios do indivíduo para pagar os seus débitos. $O$ pagamento se dá através da prática da caridade e do aperfeiçoamento moral etc. Já na reforma íntima em Chico Xavier, o indivíduo em evolução pode ser ajudado por outrem: terceiros, bons ou maus, que intervêm para o ajudar a evoluir mais rápido. Os amigos intercedem pelos entes queridos mais desafortunados, suavizando suas "provas", e os inimigos intercedem ao nos ensinar o valor da paciência e da humildade. É o que Lewgoy chama de "circuito de intercessão e graça”. Em Chico Xavier, o sistema da dívida convive com o sistema da dádiva, e em diferentes situações este último engloba o primeiro (Lewgoy, 2000).

\footnotetext{
${ }^{30}$ Lembremos de que faz parte da narrativa espírita, como já demonstramos, o exílio. Este elemento também faz parte da narrativa de formação de nosso País, na ideia de que os que aqui vieram colonizar eram a escória de marginais do velho mundo português; sem contar com a diáspora africana, que se em determinado momento foi a força braçal para enriquecer a elite portuguesa, tornou-se também um dos principais problemas para a identidade nacional.

${ }^{31}$ Para o neolamarckismo, Stepan (2005) e Stefano (2004).
} 
Lembramos que o entendimento da ciência eugênica que se faz no Brasil passa pela regeneração do indivíduo através da ação moralizadora. Ora, é sob esta lógica que atua o circuito de intercessão e graça do modelo de espiritismo de Chico Xavier, já que a ajuda externa é capaz de mitigar provas e suavizar dores, e, além disso, também aciona o "arrependimento" e a "autocorreção" do indivíduo, sendo, assim, eficaz para promover a pessoa espírita. Desta maneira é que o circuito de intercessão e graça de Chico Xavier pode ser compreendido a partir da lógica mais geral do modelo eugênico, que operou no Brasil durante o século XX.

O aprimoramento da humanidade permanece uma preocupação também nos discursos de Ellam, em seu entendimento sobre o expurgo e de como esse se dará: notadamente, não apenas através de uma reforma moral, mas também através de uma intervenção das "forças do bem". Assim, em sua versão da história, Jan Val Ellam mantém a centralidade da reforma íntima de Kardec, quando salienta a necessidade de os humanos regenerarem-se através de um "autoburilamento", e mantém também o circuito de intercessão e graça de Chico Xavier, incrementando este último, porém através da categoria nativa ajuda direta. A chegada das naves, que concluirá a expulsão dos inadequados, é este elemento.

\section{O PILOTO E AS ARMADAS CELESTIAIS: CONCLUINDO O APRIMORAMENTO RACIAL DA TERRA}

Para esclarecer a peculiar maneira como Ellam descreve o seu fim dos tempos, retornamos ao início do texto: o leitor deve recordar a recomendação de um dos membros do Atlan para que nos registrássemos em certa comunidade virtual. Este site apresenta alguns personagens importantes para o "expurgo": extraterrestres membros da Grande Fraternidade Branca, mencionada por Armond e retomada por um conjunto de livros lidos pelos espíritas $^{32}$. Também denominada de Aguias no Comando, Armadas Celestiais

\footnotetext{
${ }^{32}$ Dentre eles, Romo e Romo (2002), Orlovas (1999), Bourel-Dansot (2006), Tamburini (2007) e Rosa (1998).
} 
ou de Comando Galáctico Interestelar, esta fraternidade é uma espécie de "governo oculto" da Terra ${ }^{33}$ e tem como líder o Comandante Ashtar Sheran, que junto a outros comandantes e generais estelares, em geral homens de tez clara e cabelos longos e loiros, apresenta-se aos médiuns trajando vestes e emblemas de hierarquia militar.

É possível pensar que estas entidades espirituais não apenas se ajustam a certo ideal de pureza racial, mas também a um ethos espírita que articula as noções de obediência, retidão e ajuste moral. Sob um discurso nacionalista, enfatizando a pátria brasileira, a literatura nativa destaca a ajuda desta armada na "expulsão dos inadequados", já que não há mais alternativas para o melhoramento dos terráqueos, a não ser a intervenção saneadora dos mestres.

Ora, os escritos de Ellam são atravessados por essa noção, presente em outros movimentos milenaristas que cultuam ETs: a da intervenção saneadora desde fora do planeta Terra por parte dos verdadeiros governantes do planeta (Grunschloss, 2002), caracterizando uma espécie de golpe de Estado inevitável, que deve ser dado em breve - um golpe que, aliás, é tido como necessário e legítimo. É essa noção que parece permear a profecia de Ellam.

Há, porém, outros elementos a examinar. Devemos lembrar que nosso médium escreve seu primeiro livro nos últimos anos do século $\mathrm{XX}$. $\mathrm{O}$ contexto em que ele opera se diferencia do de Kardec e do livro $A$ Caminho da Luz, de Xavier. Ellam encontra-se na confluência de outras narrativas, ao lado da narrativa espírita: um exemplo é a ficção científica; lembramos, aliás, ao leitor, que em sua trilogia Ellam pilotava uma nave espacial, como assim faz Atlan, o "arconiano", personagem da série Perry Rhodan. Nesta série, publicada no Brasil entre 1966 e 2001, figuram heróis nascidos em um tempo anterior ao tempo das primeiras civilizações terrestres. Particularmente em "Atlan e Árcon”, título de um dos "ciclos" da série, aparece Atlan, o extraterrestre que mais influenciou a história da Terra.

Alguns elementos etnográficos ainda sugerem uma recuperação por Ellam de traços esparsos da astrofísica, em sua obra e nas marcas que imprime em sua imagem. Faz parte destes indícios o seu próprio pseudônimo, possível

${ }^{33}$ Para o "governo oculto da Terra", ver Rosa (1998). 
alusão ao físico americano James Van Allen. Também é emblemática, em sua história sobre o "projeto planeta azul", a referência à noção de "pálido ponto azul”, título de livro do popular astrônomo Karl Sagan.

\section{CONSIDERAÇÕES FINAIS}

Importa refletir que, se a narrativa de Kardec sobre exílio faz sentido para a ciência eugênica de sua época, e a de Xavier atualiza o tema da eugenia em uma composição com a cultura católica brasileira, Ellam já escreve em um peculiar momento no processo de modernização de nosso País e do mundo: um mundo dito pós-raças, mas onde os conflitos raciais são recorrentes; que atravessou a guerra fria, mas que assiste a corridas armamentistas e ameaças atômicas; que, via tecnologias construídas para a guerra, encurtou o tempo, mas onde miséria, fome e violência continuam fortemente a assolar a humanidade.

Por outro lado, Ellam incrementa o veio moralizante - muito bem aceito pelos espíritas - com elementos para o seu público em especial, simpatizante de um espiritualismo de veio ufológico. Assim, se mostrar espírita, ufólogo e admirador de astrofísica, além de trazer nomes marcantes da cultura pop, mais precisamente da ficção científica, para sua literatura é uma combinação ímpar, que desponta em sua carreira e que talvez seja seu diferencial, frente a tantos outros ufólogos espiritualistas que se têm na atualidade.

Ora, em relação às misturas frequentemente encontradas no âmbito do espiritismo, Lewgoy (2006) chama atenção para o fato de que à margem da representação de unidade nos discursos oficiais e falas do espiritismo institucional, as singularidades etnográficas apontam para atravessamentos e sincretismos "aparentemente fora de ordem" (Lewgoy, 2006, p. 154). Para Lewgoy, o que faz ter uma ideia, desde longe, de uma coesão de crenças e ritos no espiritismo é o cultivo, pelo espiritismo institucional, de uma "identidade forte", que funciona como um vetor "centrípeto", em oposição a outro modelo identitário "mais aberto, poroso, sincrético e subjetivante". A incidência do que ele denomina poderes centrais possibilita a "unificação da Babel" (Lewgoy, 2006, p. 154). 
É neste caminho que Ellam recupera elementos de diversas ordens, e numa mistura algo sincrética ele se aproxima tanto do espiritismo mais ortodoxo (Kardec, Chico Xavier), quanto de vertentes espíritas mais heterodoxas (Armond, Maes), assim como da ufologia e da ficção científica. Não obstante, o médium não traz uma proposta original ao ponto de oferecer uma religiosidade de nova ordem ${ }^{34}$ : a "mistura" que realiza, faz-se e se completa no espiritismo; é esta doutrina que engloba todo o resto. Assim é que nos parece ser importante que ele não negue ao ser apontado como a reencarnação de Allan Kardec.

Ellam consegue revisitar o aperfeiçoamento dos seres e a expulsão dos inadequados de Kardec e Xavier, incrementando-o com a esquina do povo de Alt'Lam, e por fim situar de forma específica os grupos que o seguem; fala para os natalenses sobre sua história com os americanos, para os ufólogos sobre os extraterrestres e para os espíritas sobre ser Allan Kardec e também sobre ser um antigo piloto de nave espacial que aprendeu há muitos milênios a fazer codificação. Todos estes elementos juntam-se e sinalizam: Ellam expressa anseios que são coletivos, e nesse sentido é que sua versão da narrativa criada por Chico Xavier não deve ser percebida como a idiossincrasia de um grupo. Ele responde a anseios oriundos do próprio movimento espírita brasileiro: conteúdos como os apresentados em seus livros já haviam sido atualizados por outros médiuns no Brasil, antes mesmo que ele escrevesse a sua primeira linha.

Talvez a distinção e o apelo que Ellam consegue ter residam justamente no fato de ele conseguir indigienizar os panoramas de crenças e imagens em fluxo (Appadurai, 1990), ao trazer uma história universal para a "esquina" do Brasil e ao contemplar - e misturar - aprimoramento racial e moral com ufologia, astrofísica, ficção científica e espiritismo, para um público ávido desses links. Neste sentido, ele reaviva memórias e mobiliza pessoas, expressando, como profeta, anseios emocionais, mas também cognitivos e

${ }^{34}$ O Grupo Atlan não se identifica enquanto grupo religioso, e sim um grupo "de estudo" que legitima o discurso espírita de que este "estudo" é atravessado por elementos "religiosos, filosóficos e científicos".

Debates do NER, Porto Alegre, Ano I3, N. 2I P. I23-I5O, JAN./Jun. 2012 
volitivos do universo espírita brasileiro, particularmente para os espíritas desregulados das federações.

É de se pensar, ao fim e ao cabo, que talvez o espiritismo careça de novos heróis, performando novas estruturas de afeto. Talvez a curiosidade cristã de André Luiz, o repórter do além, ou a abnegação de Bezerra de Menezes, o médico dos pobres, esses que escreveram pela mão de Chico Xavier, o médium mineiro, chamado de homem coração, não mais respondam completamente aos anseios que povoam o movimento espírita que se faz no Brasil atualmente. Talvez seja necessário um piloto de guerra, navegando pelo espaço em um disco voador, e antigo seguidor de Lúcifer, para responder às mesmas perguntas de outra forma. Melhor dizendo, para falar do ansiado expurgo com o qual sonham os espíritas de outra maneira.

\section{REFERENNCIAS}

APPADURAI, Aajun. Disjunção e diferença na economia cultural global. In: FEATHERSTONE, Mike (Org.). Cultura Global: nacionalismo, globalização e modernidade. Petrópolis: Vozes, 1990.

ARANHA FILHO, Jayme Moraes. Inteligência Extraterrestre e Evolução: as especulaçôes sobre a possibilidade de vida em outros planetas no meio científico moderno. Dissertação (Mestrado em Antropologia Social). UFRJ, 1990.

ARMOND, Edgard. Os Exilados da Capela: Esboço Sintético da Evolução Espiritual do Mundo. 25. ed. São Paulo: Aliança, 1990.

AUBRÉE, Marion. De l'Histoire au Mythe - La dynamique des romans spirites au Brésil. In: MARTIN, J. B. (Org.). Le Déf magique, éd. P.U.L., Lyon, 1994. p. 207-217, (vol. 1).

BAKHTIN, Mikhail. Marxismo e filosofia da linguagem. São Paulo: HUCITEC, 1997.

BASTIDE, Roger. As Religiōes Africanas no Brasil: contribuição a uma sociologia das interpenetrações de civilizações. Vol. II. São Paulo: Livraria Pioneira Editora/EDUSP, 1971. 
BOUREL-DANSOT, Gabrielle. Os Ensinamentos dos Grandes Mestres da Fraternidade Branca. Rio de Janeiro: Madras, 2006.

CALIMAN, Luciana. Dominando Corpos, Conduzindo Açôes: genealogias do biopoder em Foucault. In: JACÓ-VILELA, Ana Maria; CEREZZO, Antônio Carlos; RODRIGUES, Heliana de Barros Conde. (Orgs.). Clio-Psyché - Subjetividade e História. Juiz de Fora: Clio Edições Eletrônicas, 2006.

CASCUDO, Luís da Câmara. História da Cidade do Natal. 3. ed. Natal: IHGRN, 1999.

CAVALCANTI, Maria Laura Viveiras de Castro. O mundo invisivel. Cosmologia, sistema ritual e noção de pessoa no espiritismo. Rio de Janeiro: Zahar, 1983.

COSTA, Jurandir Freire. A Face e o Verso: estudos sobre o homoerotismo II. São Paulo: Escuta, 1995.

. Ordem Médica e Norma Familiar. Rio de Janeiro: Edições Graal, 1999.

CRUZ, Inácio. Doutor Fritz Andou de Disco Voador: hibridizações e sincretismos na terapia espiritual de Chico Monteiro. Dissertação (Mestrado). Juiz de Fora, Universidade Federal de Juiz de Fora, Programa de Pós-Graduação em Ciências da Religião, 2007.

ELLAM, Jan Val. Reintegração Cósmica. (Trilogia Queda e Ascensão Espiritual Livro 1). 2. ed. São Paulo: Navegar Editora, 1996.

- Caminhos Espirituais - Livre Arbitrio (Trilogia Queda e Ascensão Espiritual Livro 2). São Paulo: Zian, 1997. - Carma e Compromisso - Filhos das Estrelas (Trilogia Queda e Ascensão Espiritual Livro 3). São Paulo: Zian, 1998.

. Registro gravado de reunião do Grupo Atlan 04/04/2000, 2000.

2005 . . A Sétima Trombeta do Apocalipse: a Volta de Jesus. São Paulo: Zian, 
FERREIRA, Artur. Ramatis, Sábio ou Pseudo-Sábio?. São Paulo: Opinião/ EME, 1997.

- Espiritismo x Ramatisismo: Análise Crítica dos Ditados do Espírito Ramatis. São Paulo: EME, 2012.

FOUCAULT, Michel. História da sexualidade I: a vontade de saber. 16. ed. Rio de Janeiro: Graal, 1988.

As técnicas de si. In: Espaço Michel Foucault, 1994. Disponível em: http://www.unb.br/fe/tef/filoesco/foucault. Acesso em: 23 set. 2007.

GARCÍA MÁRQUEZ, Gabriel. O Afogado Mais Bonito do Mundo. In: A Incrivel e Triste História da Cândida Erêndira e Sua Avó Desalmada. Rio de Janeiro: Record, 1998.

GIUMBELLI, Emerson. Em Nome da caridade: assistência social e religião nas instituições espíritas. Vol. I. Projeto Filantropia e Cidadania. Núcleo de Pesquisa - ISER. Rio de Janeiro, 1995.

. Zélio de Moraes e as origens da umbanda. In: SILVA, Vagner Gonçalves da (Org.). Caminhos da Alma: memória afro-brasileira. São Paulo: Summus, 2002.

GRÜNSCHLOß, Andreas. "Quando entramos na nave espacial do meu pai”: Esperanças cargoísticas e cosmologias milenaristas nos novos movimentos religiosos de UFOS. Revista de Estudos da Religião - REVER n. 3. Pós-Graduação em Ciências da Religião. PUC/São Paulo. 2002. p. 19-44. Disponível em: http://www.pucsp.br/rever/rv3_2002/p_andrea.pdf. Acesso em: 10 set 2011.

KARDEC, Allan. O Livro dos Espiritos. 79. ed. Brasília, FEB, 1997.

LAQUEUR, Thomas. Inventando o sexo: corpo e gênero dos gregos a Freud. Rio de Janeiro: Relume Dumará, 2001.

LEWGOY, Bernardo. Os Espiritas e as Letras: um Estudo Antropológico Sobre Cultura Espírita e Oralidade no Espiritismo Kardecista. São Paulo: FFLCH-USP. Tese (Doutorado), 2000. 
- Representaçôes de ciência e religiāo no espiritismo kardecista - Antigas e novas configurações. Porto Alegre: Civitas, v. 6, n. 2, p. 151-167, jul./dez. 2006.

LEWIS, James R. The Gods have landed: New religions from other worlds. In: LEVIN, James R. (Ed.). SUNY Press/University of New York Press, Albany, 1995.

LOPES, Edmilson. A Construção Social da Cidade do Prazer. Urbanização turística, cultura e meio ambiente em Natal (RN). Tese (Doutorado). IFCH, Campinas, Unicamp, 1997.

MADUREIRA, Antoniette. Vassouras, ciganas e extraterrestres: médiuns e emoções no campo religioso espírita de Natal (RN). Tese (Doutorado). Recife, PPGA/UFPE, 2010.

MAES, Hercílio. Mensagens do Astral. (espírito Ramatís). Rio de Janeiro: Freitas Bastos, 1996.

MACHADO, Carly. Imagine se tudo isso for verdade: o movimento raeliano entre verdades, ficçôes e religiōes da modernidade. IFCH/UERJ. Tese (Doutorado), 2006.

MENEZES, Jaileila de Araújo. Cuidado de Si e Gestão da Vida: da ética grega ao biopoder. In: Revista do Departamento de Psicologia da UFF. v 14, n. 2, 2002. p. 95-109.

MIGUEL, Sinuê. Espiritismo e política: o compasso dos espíritas com a conjuntura dos anos 1930/1940. In: Debates do NER, Porto Alegre, ano 10, n.15, jan./ jun. 2009, p. 39-70.

MONTEIRO, Chico. Eu viajei num disco voador. Miraí: Editora Mirahí, 1995.

ONOFRE Jr. Manuel. Guia da Cidade do Natal. Natal: EDUFRN, 2002.

ORLOVAS, Maria Silva. Os Filhos de Órion: a Chegada da Hierarquia da Luz. Rio de Janeiro: Madras, 1999. 
ORTIZ, Renato. A morte branca do feiticeiro negro. 2. ed. São Paulo: Brasiliense, 1999.

PARTRIDGE, Christopher Hugh. UFO Religions. New York: Routledge, 2003.

PÊCHEUX, Michel. Análise Automática do Discurso (AAD-69). In: GADET, Françoise; HAK, Tony. (Org.). Por uma Análise Automática do Discurso: uma introdução à Obra de Michel Pêcheux. Campinas: UNICAMP, 1990.

RENARD, Jean-Bruno. Les Extraterrestres. Une nouvelle croyance religieuse? La Flèche, Éditions du Cerf, 1987.

- L'Homme Sauvage et l'Extraterrestre: deux figures de l'imaginaire évolutionniste, Diogène, n. 127, p. 70-88, 1984.

ROMO, Carmen; ROMO, Rodrigo. Confederação Intergaláctica II: a Cosmogênesis dos Criadores. São Paulo, Madras, 2002.

ROSA, Henrique. O Governo Oculto do Mundo: o Trabalho da Hierarquia Oculta. São Paulo: Editora Portal, 1998.

SCHWARCZ, Lilia Mertiz. O espetáculo das raças: cientistas, instituições e questão racial no Brasil. São Paulo: Companhia das Letras, 2001.

SPEER, Herbert. A Grande Missão Celeste de Ashtar Sheran à Humanidade da Terra: O Comandante-em-Chefe da Frota Extraplanetária Comunica ao Mundo sua Incubência. Rio de Janeiro: Pongetti, 1973.

STEFANO, Waldir. Relações entre eugenia e genética mendeliana no Brasil. Octavio Domingues. In: MARTINS, Roberto de Andrade; MARTINS, Lilian Alchueyr Pereira; SILVA. Cibele Celestino; FERREIRA, Juliana Mesquita Hidalgo (Eds.). Filosofia e história da ciência no Cone Sul: $3^{\circ}$. Encontro. Campinas. AFHIC, 2004. p. 486-495.

STEPAN, Nancy. A hora da eugenia: raça, gênero e nação na América Latina. Rio de Janeiro: Fiocruz, 2005. 
. Eugenia no Brasil, 1917-1940. HOCHMAN; ARMUS (Orgs.). Cuidar, Controlar, Curar: Ensaios históricos sobre saúde e doença na América Latina e Caribe. Rio de Janeiro, Fiocruz. Coleção História e Saúde, 2004. STOLL, Sandra Jacqueline. Espiritismo à brasileira. São Paulo: Edusp/ Orion, 2003.

. Religião, ciência ou auto-ajuda? Trajetos do Espiritismo no Brasil. Revista de Antropologia. São Paulo, USP, v. 45 n. 2, 2002. . Entre dois mundos: o espiritismo da França e no Brasil. São Paulo, Tese (Doutorado), Universidade de São Paulo, 1999.

TAMBURINI, Dariana. Seres de Luz e os 12 Raios da Grande Fraternidade Branca. São Paulo: Alfabeto, 2007.

VAL EOM. Os Muitos Caminhos da Vida. São Paulo, Zian, 2003.

VALLEE, Jacques. Messengers of Deception: UFO Contacts and Cults. Ronin Publishing, 1979.

VERONESE, Michelle. Deuses de Outros Mundos: O culto a discos voadores e extraterrestres. Dissertação (Mestrado) Pontifícia Universidade Católica de São Paulo. Programa de Pós-Graduação em Ciências da Religião. 2006. XAVIER, Francisco Cândido. A Caminho da Luz. (pelo espírito Emmanuel). 24. ed, Brasília: FEB, 1997. 